\title{
Development of Specific Tools for Analysis and Quantification of Pre-ignition in a Boosted SI Engine
}

\author{
Jean-Marc Zaccardi, Laurent Duval, Alexandre Pagot \\ IFP
}

Copyright @ 2009 SAE International

\begin{abstract}
Recent developments on highly downsized spark ignition engines have been focused on knocking behaviour improvement and the most advanced technologies combination can face up to $2.5 \mathrm{MPa}$ IMEP while maintaining acceptable fuel consumption. Unfortunately, knocking is not the only limit that strongly downsized engines have to confront. The improvement of low-end torque is limited by another abnormal combustion which appears as a random pre-ignition. This violent phenomenon which emits a sharp metallic noise is unacceptable even on modern supercharged gasoline engines because of the great pressure rise that it causes in the cylinder (up to $20 \mathrm{MPa}$ ).
\end{abstract}

The phases of this abnormal combustion have been analysed and a global mechanism has been identified consisting of a local ignition before the spark, followed by a propagating phase and ended by a massive autoignition. This last step finally causes a steep pressure rise and pressure oscillations.

One of our objectives was to evaluate the sensitivity of an engine to pre-ignition regarding its design and settings. Therefore, in addition to our comprehension work, we have developed a first methodology based upon robust statistics to define new reliable and repeatable criteria to quantify this stochastic pre-ignition but also to detect each of its occurrence, suggesting the possibility of an on-line detection during steady state and transient operation as well. The statistical approach also showed that the distributions of well chosen combustion indicators are strongly altered by pre-ignitions. A second methodology was then defined to evaluate the influence of different parameters on pre-ignition by quantifying this alteration. This analysis notably gives the opportunity to achieve a deeper analysis of pre-ignition during engine development on test bench.

\section{INTRODUCTION}

Spark ignition engines used today offer the great advantage of limiting local pollutants emissions $(\mathrm{HC}, \mathrm{CO}$ $\& \mathrm{NO}_{\mathrm{x}}$ ) thanks to the excellent adequacy between their operating mode (lambda one) and their simple and low cost after-treatment system. Despite this fundamental asset, those engines are badly considered concerning the greenhouse gases emissions because competitor Diesel engines reach an average $\mathrm{CO}_{2}$ emissions $20 \%$ lower thanks to an overall good efficiency.

Fuel consumption of $\mathrm{SI}$ engines has now to be reduce to meet future $\mathrm{CO}_{2}$ legal emission agreements but also environmentally-friendly customer demands. In light of this, the combination of air charging and downsizing is one of the most promising solution because of its low technological cost and because it helps to reduce pumping and friction losses.

Unfortunately, the combustion mechanism of SI engines can be disturbed by abnormal phenomena [1]. Two major kinds of uncontrolled combustion can appear.

- Surface ignition : in this case, the ignition of fresh mixture is not controlled by a spark at a predetermined crank angle. This ignition takes place at variable timing on an overheated component (like a valve or a spark plug) because of the unbalanced thermal transfer between the energy brought by the combustion and the thermal dissipation within the engine. The main feature of this kind of pre-ignition is that it progressively degenerates since the overheated component is getting warmer and warmer cycle after cycle as a consequence of the early timing combustion (hence it is generally called a "run away pre-ignition"). This first abnormal combustion can be fought with an optimised combustion chamber using for example an adapted thermal range for the spark plug and improving the cooling circuit to remove potential hot surfaces.

- Auto-ignition of fresh charge : this self ignition is a consequence of appropriate thermodynamic conditions inside the combustion chamber. Indeed, if the fresh mixture is strongly compressed and heated up the auto-ignition delay can be reduced. Knocking and CAl combustion modes (Controlled Auto Ignition) are the best known examples of autoignition.

More recently, developments of highly charged gasoline engines showed that a violent form of sporadic preignition can appear under high loads at low engine 
speeds. Because of its occasional characteristic, this new kind of uncontrolled combustion does certainly not correspond to a classical surface pre-ignition.

This phenomenon has already been mentioned and described in numerous previous papers. Our aim is not to discuss the potential causes of this pre-ignition. In fact, many hypotheses have already been formulated to explain this phenomenon but no one has really been confirmed and it is possible that several factors could be combined to provoke this dangerous combustion as well [2] [3] [4] [5] [6] [7] [8] [9] [10] [11] [12] [13].

We focus here on new methodologies of analysis, quantification and control of this violent combustion. The aim is of course to minimize its occurrence frequency and its intensity in order to reach safely higher low end torque and to maximise the consumption reduction with a highly downsized engine.

The first part of this paper gives a description of preignition based upon cylinder pressure analysis and direct in-cylinder imaging.

The second part introduces the statistical data processing that has been used to characterize this phenomenon.

Then, the third and fourth parts describe two strategies usable on board and on test bench to achieve a real-time detection and control of pre-ignition.

\section{EXPERIMENTAL APPARATUS}

\section{ENGINE}

Results shown in this paper were obtained on a single cylinder engine used at IFP for combustion studies and especially for highly charged $\mathrm{SI}$ engines. The main features of our selected technical definition are summarized in Table 1 and a simplified CAD view of the combustion chamber is given in Figure 1.

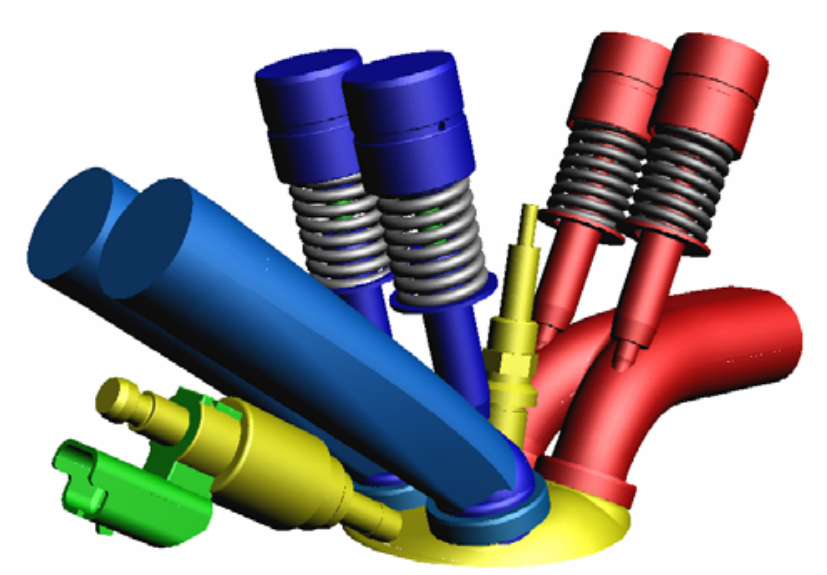

Figure 1 : CAD view of the pent roof cylinder head

\begin{tabular}{l|l} 
Type & $\begin{array}{l}\text { Pent roof shape } \\
\text { 4 valves }\end{array}$ \\
\hline Bore $(\mathrm{mm})$ & 69 \\
\hline Stroke $(\mathrm{mm})$ & 80.5 \\
\hline Displacement $\left(\mathrm{cm}^{3}\right)$ & 301 \\
\hline Compression Ratio & $9.5: 1$ \\
\hline Connecting rod length $(\mathrm{mm})$ & 139 \\
\hline Piston shape & Flat \\
\hline Intake duration (CAD at 1 $\mathrm{mm})$ & 190 \\
Inlet Valve Opening (CAD at 1 mm) & 10 ATDC \\
Maximum intake valve lift (mm) & 7.3 \\
\hline Exhaust duration (CAD) & 210 \\
Exhaust Valve Closure (CAD at 1 mm) & 10 BTDC \\
Maximum exhaust valve lift (mm) & 8.2
\end{tabular}

Table 1 : Engine specifications

Manifold Port Fuel Injection and Direct Injection (DI) modes were used on this engine. The gasoline direct injection was performed with a multi-hole injector placed under the intake ducts with a special spray targeting. The characteristics of this injector are summarized in Table 2.

\begin{tabular}{l|l} 
Injector type & $\begin{array}{l}\text { Multi-hole }-6 \text { holes } \\
\text { Oval spray }\end{array}$ \\
\hline Injection pressure & $6-20 \mathrm{MPa}$ \\
\hline Static flow & $\begin{array}{l}720 \mathrm{~g} / \mathrm{min} @ 10 \mathrm{MPa} \\
\text { (n-heptane) }\end{array}$ \\
\hline Single beam angle & $16^{\circ}$
\end{tabular}

Table 2 : Multi-hole injector specifications

The ignition was realised with a high energy DELPHI ignition coil $(110 \mathrm{~mJ})$ combined with a centrally located NGK spark plug which had an iridium centre electrode and a heat rating number of 8 (NGK rating).

Rotating and reciprocating forces were balanced to achieve safely our full load objectives of 3.0 MPa IMEP at $1000 \mathrm{rpm}$ and $2.5 \mathrm{MPa}$ IMEP at $5500 \mathrm{rpm}\left(115 \mathrm{~kW}_{\mathrm{i}} / \mathrm{L}\right)$.

\section{TEST BENCH}

This study was realised on a special test bench designed for single cylinder engines. Oil, coolant and fuel were supplied by electrically driven pumps. Several temperature and pressure measurements were made on the coolant, oil, fuel, intake and exhaust circuits to settle the different operating points and to supervise the engine.

Intake pressure was recorded with an absolute pressure transducer (KULITE XT-123B-190-50A). Exhaust and incylinder pressures were recorded with water-cooled 
relative pressure transducers (AVL QC43D \& KISTLER 6043A60).

There was no turbocharger on our engine, but the test bench was equipped with a compressor for the intake line (sonic flow meter up to $0.35 \mathrm{MPa}$ abs) and a flap in the exhaust line to simulate the backpressure of a turbine.

There was no ECU associated to this engine. Injection and ignition were manually controlled with a specific software developed at IFP. This way, we could control the engine as we want for steady state running conditions even with multiple injection and ignition timings during the same cycle.

All the measurements were recorded and analysed with an in-house software.

\section{PRE-IGNITION PROCESS}

\section{DESCRIPTION BASED UPON CYLINDER PRESSURE}

We propose here to sum up the description of the abnormal combustion process based upon cylinder pressure analysis. A full description is already available in a previous paper [2].

The observation of this uncontrolled combustion on test bench is actually mainly made on in-cylinder pressure traces. A simple example with a violent pre-ignition compared to a normal combustion is given in Figure 2 . Cycles $n^{\circ} 8$ and 10 show a normal combustion with an initiation at the spark plug and a flame propagation through the combustion chamber. In this two cycles, we can observe the late ignition and hence combustion timing necessary to cope with the knocking phenomenon. Cycle $n^{\circ} 9$ is an example of pre-ignition. The pressure difference between cycles $n^{\circ} 9$ on the first hand and $n^{\circ} 8$ and 10 on the other hand just before the spark is an obvious evidence that combustion began too early.

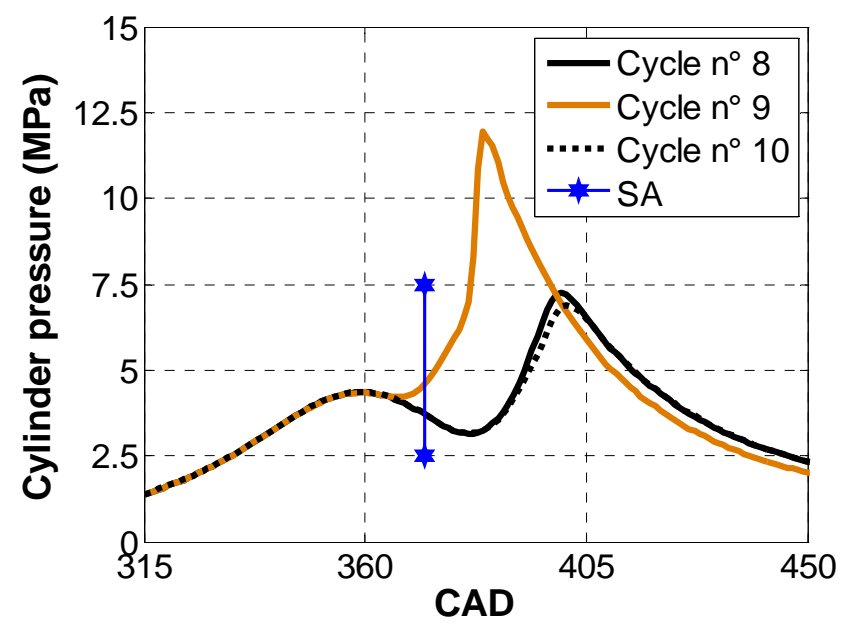

Figure 2 : Pre-ignition example
This kind of pre-ignition can be so violent that a single occurrence can definitively damage the moving parts (especially the connecting rod). This abnormal combustion is all the more dangerous that it is impossible to fight against it simply by setting differently the spark advance or the air fuel ratio contrary to a classical knocking combustion.

A simplified rate of heat release ROHR can be calculated from the cylinder pressure and combustion chamber volume (see Figure 3).

$$
R O H R=\frac{1}{V_{c y l}} *\left(\frac{1}{\gamma-1} * V * d P+\frac{\gamma}{\gamma-1} * P * d V\right)
$$

$\gamma:$ polytropic coefficient

$P$ : cylinder pressure (MPa)

$V:$ combustion chamber volume $\left(\mathrm{dm}^{3}\right)$

$V_{c y l}:$ displacement $\left(\mathrm{dm}^{3}\right)$

Then, based upon the cylinder pressure and this simplified ROHR analyses, it is possible to propose a three steps general mechanism for pre-ignition [2].

1. The ignition takes place before the spark occurrence with a variable timing for each pre-ignition and anywhere in the combustion chamber (as far as we know using only one in-cylinder pressure transducer).

2. Disregarding the early timing, the second part of the combustion seems to be quite normal with a heat release which is comparable to a normal combustion.

3. The third and last part of combustion is clearly faster than the second part. The pre-ignition somewhere in the combustion chamber combined with the compression at high load provoke such an increase of temperature and pressure that a bulk auto-ignition occurs.

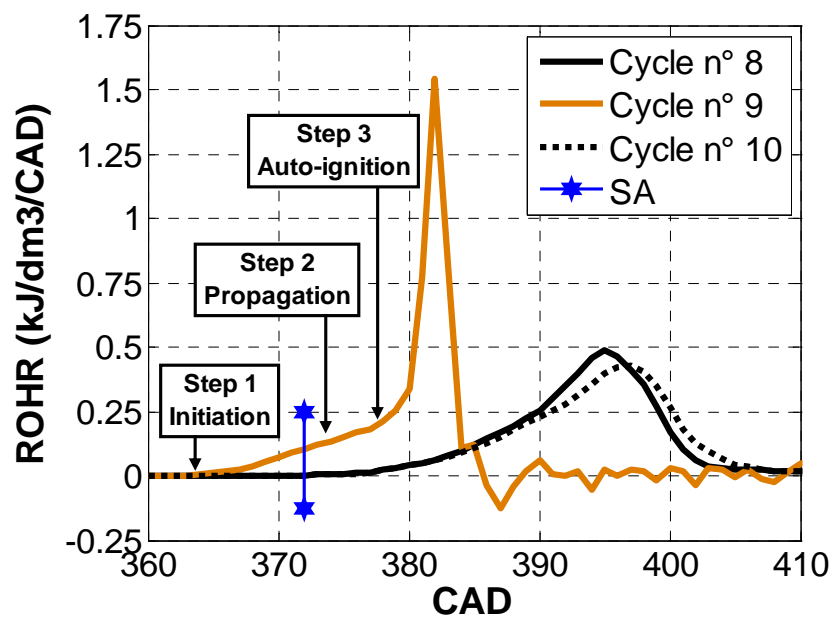

Figure 3 : Pre-ignition general mechanism

The final bulk auto-ignition looks like a knocking combustion except that the fresh mixture quantity concerned by this auto-ignition is far greater than for a classical knocking phenomenon (sometimes more than $50 \%$ of the total fresh mixture quantity). 
Pressure oscillations are not clearly visible in the previous example because cylinder pressure was recorded at each crank angle degree. A ten times faster data acquisition rate can illustrate those pressure oscillations (see Figure 4). Besides, our analysis showed that those oscillations have roughly the same frequency content of a classical knocking combustion obtained on the same engine and evaluated beforehand from Bessel functions. Moreover, parasitic mechanical resonance frequencies can also appear in the frequency content due to the violence of the phenomenon.

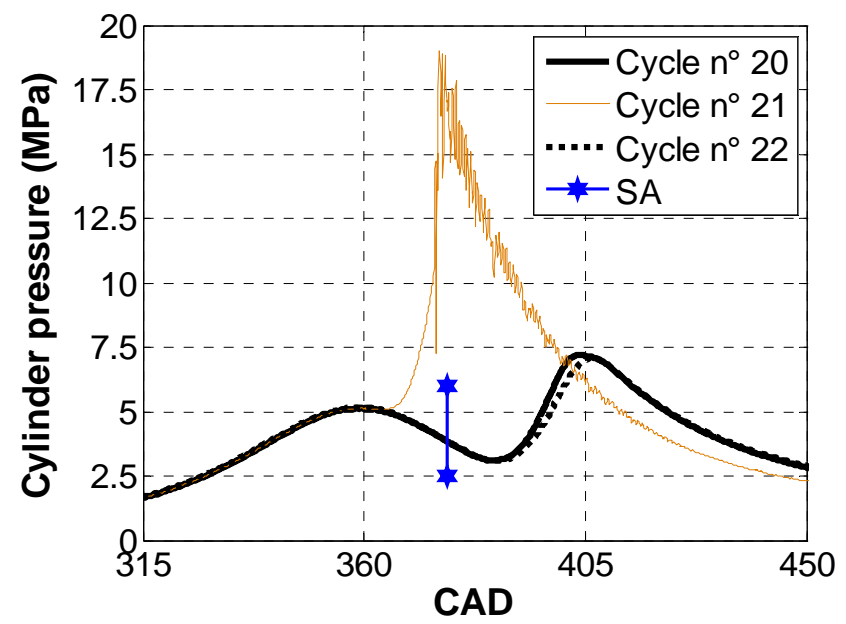

Figure 4 : Final bulk auto-ignition with associated pressure oscillations

This result shows that we can use not only the same sensor to detect knock and pre-ignition, but also the same kind of methodology for the data analysis and treatment.

\section{DESCRIPTION BASED UPON IMAGING}

\section{Imaging system}

Numerous tests were made to find a special operating point with a high frequency of pre-ignitions but always with limited intensities. The selected settings are summarized here below in Table 3 (reference for ignition and injection timings is taken on the combustion TDC).

\begin{tabular}{l|l} 
Engine speed (rpm) & 1000 \\
\hline IMEP (MPa) & $\approx 1.8$ \\
\hline $\mathrm{T}_{\text {coolant }}=\mathrm{T}_{\text {oil }}\left({ }^{\circ} \mathrm{C}\right)$ & 95 \\
\hline Spark Advance & from $\mathrm{KL}$ to $\mathrm{KL}-10 \mathrm{CAD}$ \\
\hline Start of Injection (CAD BTDC) & from 220 to $260 \mathrm{CAD}$ \\
\hline Intake temperature $\left({ }^{\circ} \mathrm{C}\right)$ & from 30 to 50 \\
\hline Boost pressure $(\mathrm{MPa})$ & $\approx 0.18$
\end{tabular}

Table 3 : Operating point for direct pre-ignition visualisations
A non-intensified colour Charge-Coupled Device (CCD) camera was used to visualise pre-ignition in the combustion chamber (see Table 4). We decided not to use any additional light source relying only upon the light that the combustion would emit itself.

\begin{tabular}{l|l} 
Type & $\begin{array}{l}\text { IDS uEye UI-2210-M } \\
\text { VGA Camera - CCD Sensor }\end{array}$ \\
\hline Resolution & $640 * 480$ \\
\hline Colour & Colour \\
\hline Start timing (CAD) & $\begin{array}{l}4.5 \text { CAD before Spark } \\
\text { Advance (SA) }\end{array}$ \\
\hline Opening duration (CAD) & 9
\end{tabular}

Table 4 : Main characteristics and settings of the camera

The camera was mounted on an air-cooled endoscope placed on the flywheel side of the cylinder head. The field of view with such an assembly is given in Figure 5.

The opening duration and start timing of the camera imply that during a normal combustion only a small bright point corresponding to the spark between the spark plug electrodes is visible in the middle of the combustion chamber (the location of the spark initiation point is surrounded by a white dashed circle in Figure 5).

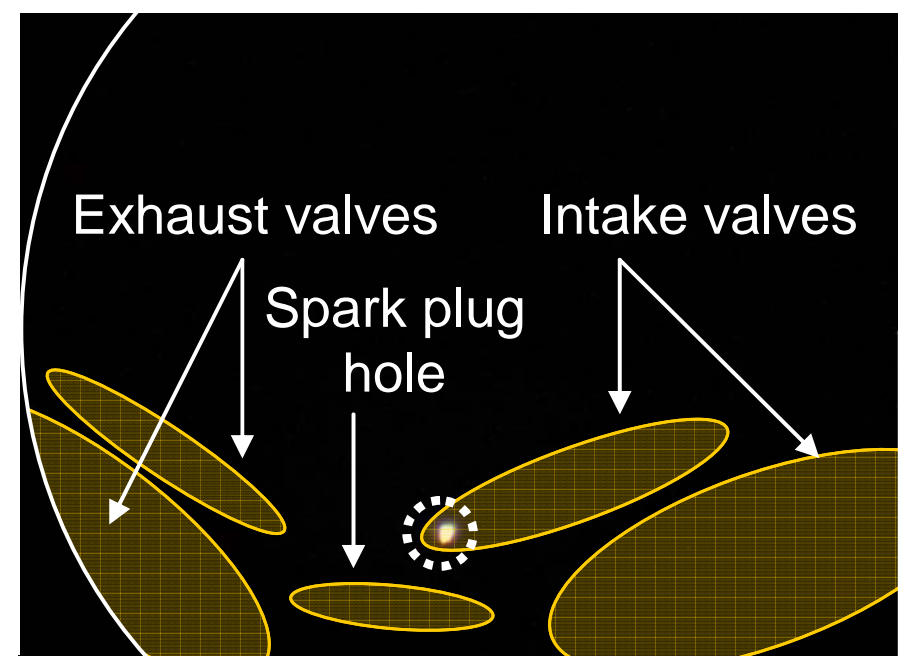

Figure 5 : Field of view in the combustion chamber with spark position indicated by dashed circle

$\underline{\text { Image processing }}$

Image processing is relatively involved due to acquisition settings : the light sources are essentially combustion related, leading to extreme contrast conditions (dark and bright areas), combined with a number of non-linear disturbances than should be removed before image enhancement, to avoid noise amplification. Figure 6 displays a detail of an image (top) along with its histogram (bottom) for each red, green and blue colour plane. Colour intensities are scaled between 0 (dark) and 
1 (bright) and represented on the horizontal axis, while the colour proportions, between 0 (rare) and 1 (frequent) are represented on the vertical axis with a logarithmic scale. Dark intensities are thus prominent (left end), with a fairly low proportion of intermediate intensities, as indicated by "orders of magnitude" decreases in the central part of the histogram. Let us precise that this image contains a pre-ignition even if it is rather invisible at this time.
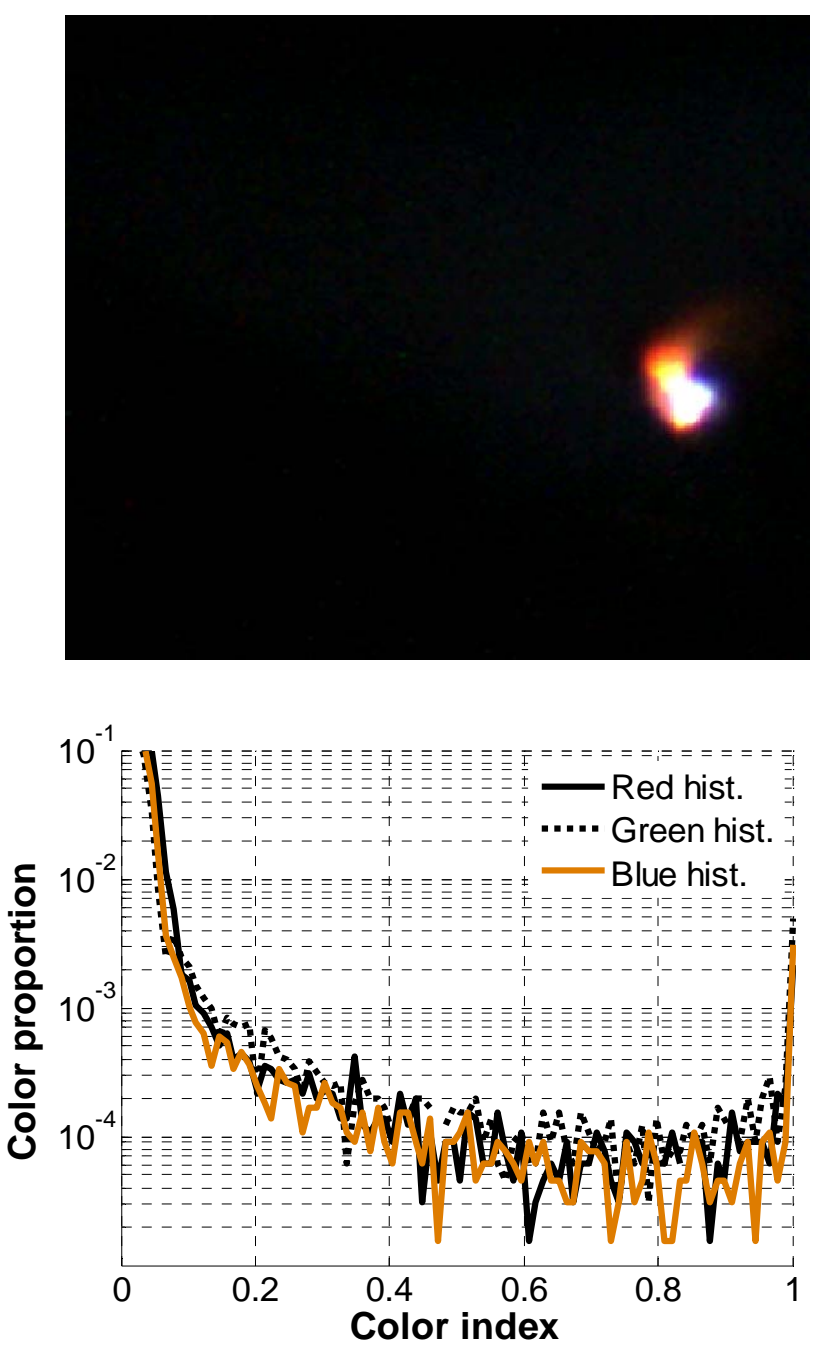

Figure 6 : Image example (top) and its color histogram (bottom)

As a consequence, standard contrast enhancement methods based on histograms may fail in providing insight to the non visible parts of the image.

The proposed processing method is based on non-linear image denoising and enhancement based on the discrete wavelet transform (we refer to [14] for a detailed exposition on wavelet transforms). The latter constitutes an alternative to the Fourier transform which is better suited to local features (e.g. contours) preservation. It consists in iteratively filtering low and high frequencies of the image rows and columns. The result of this decomposition on two levels is given in Figure 7. The top left sub-image corresponds to a filtered and sub-sampled approximation of the image in Figure 6 (top), while other sub-images contain mid-range and high frequency details. This decomposition preserves all the information since the sub-images may be recombined by the inverse wavelet transform to recover the original image.

We observe in Figure 7 (coloured) random noise components in the details, as well as distinct values located around the bright spot location. Moreover the approximation now exhibits (in light blue) information in its centre part that enhances a potential previously invisible reaction zone. Denoising with wavelet transforms basically consists in cancelling noise related coefficients, while retaining contour information to prevent image over-smoothing, as proposed in [15]. In this work, we have used a slightly more efficient decomposition, called the dual-tree wavelet transform [16], which yields state-of-the-art performance for multichannel and especially colour image denoising [17].
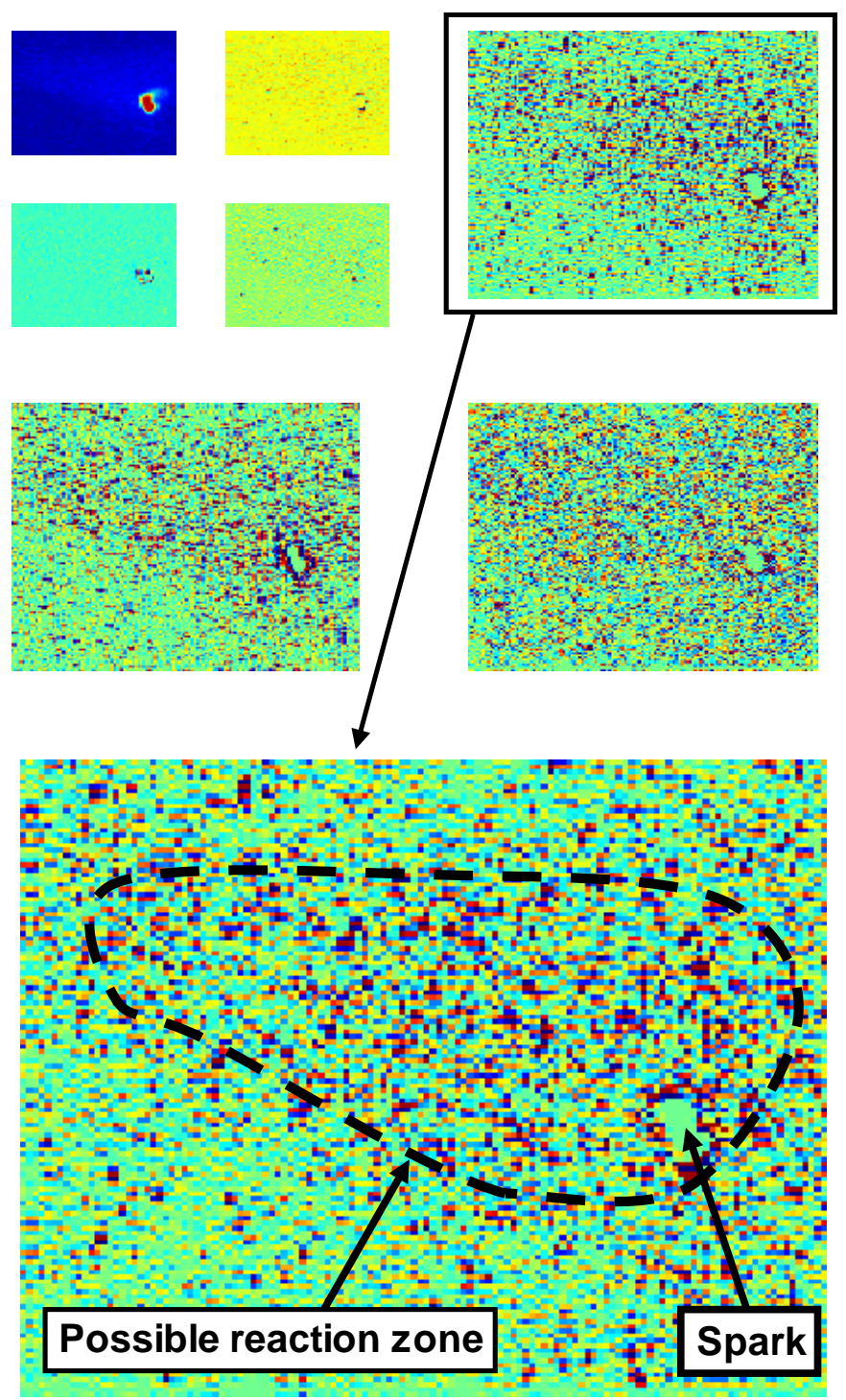

Figure 7 : Two-level wavelet decomposition of the image in Figure 6 


\section{$\underline{\text { Results }}$}

The main steps of the combustion process during a preignition are presented once again here below with images directly taken inside the combustion chamber (see Figure 8).
Since the camera was triggered at a constant timing, we could not analyse the development of a single event. What we propose here below is a description based upon four pre-ignition cycles with different timings and intensities so as to illustrate the main steps of the combustion.

\section{Cylinder pressure}
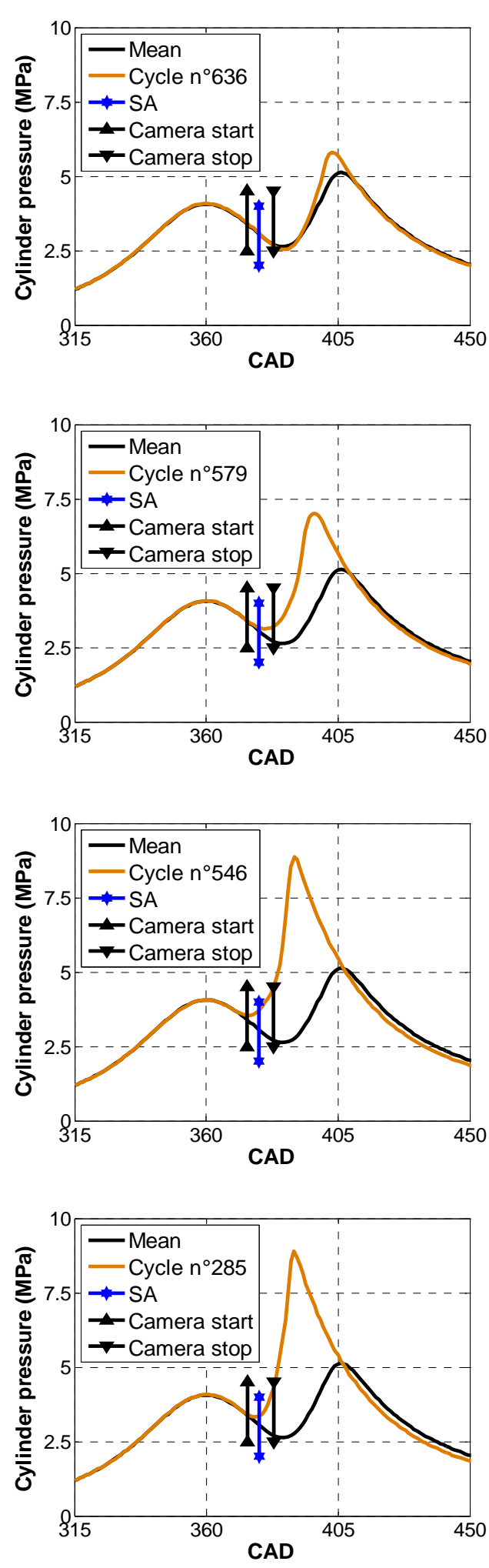

Raw images
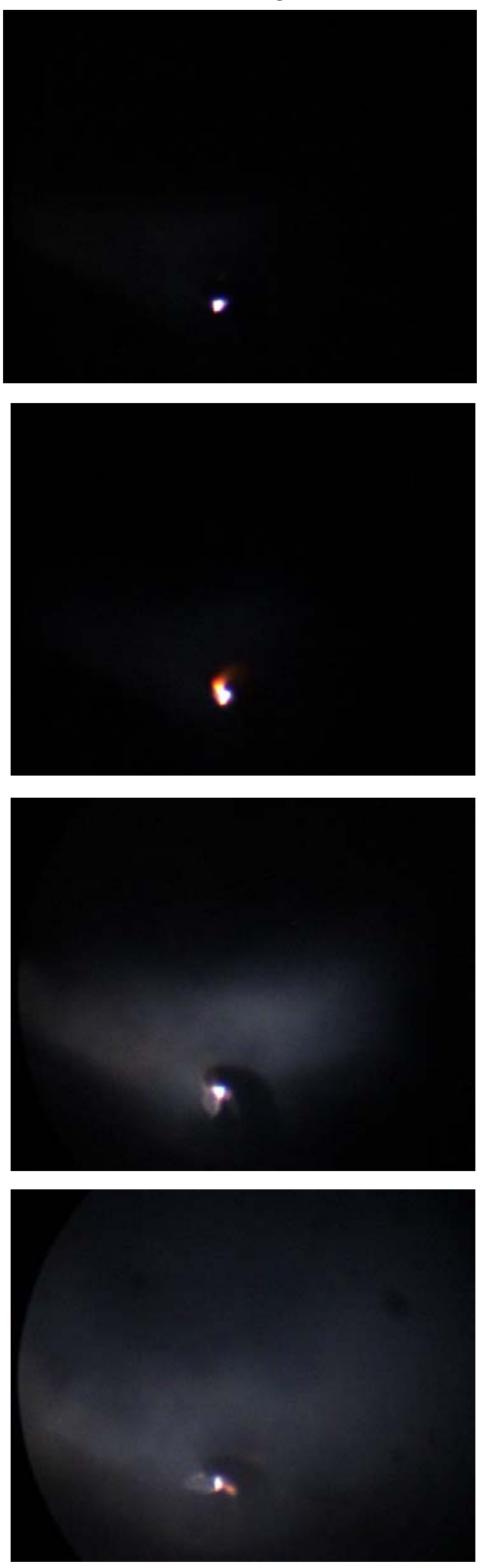

Processed images
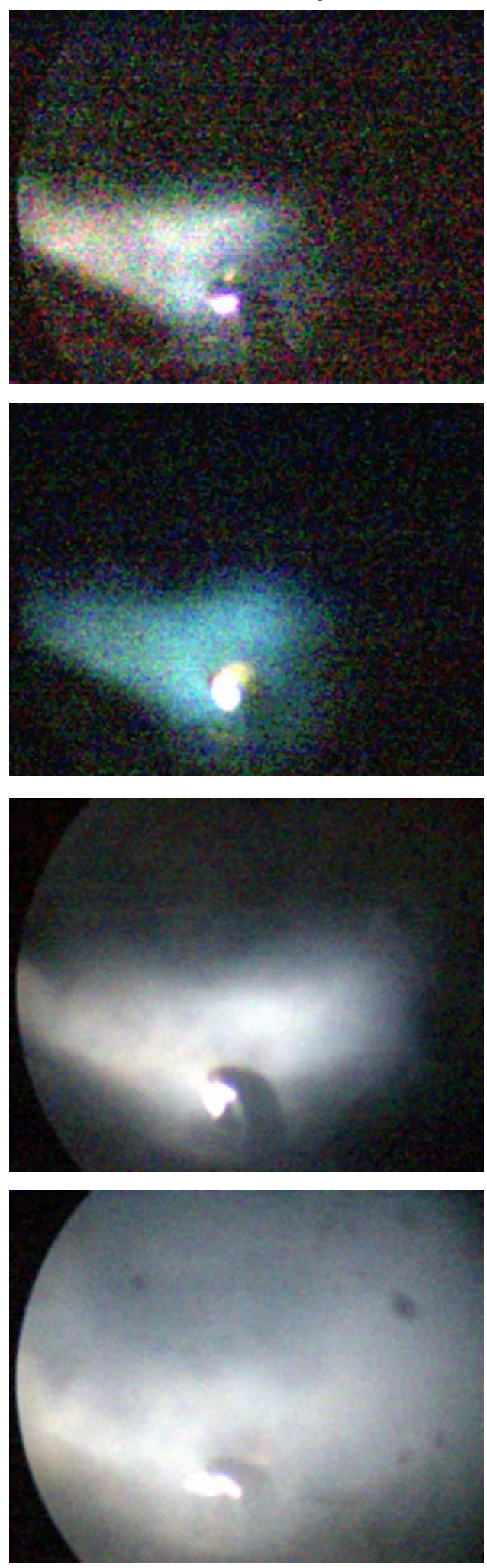

Figure 8 : Examples of pre-ignitions with different timings and intensities 
Regarding the cylinder pressure, cycle $n^{\circ} 636$ does not especially bring to light any pre-ignition. But if we take a closer look at the processed image, we can notice that a reaction zone is visible on the exhaust side of the combustion chamber. We assume here that a preignition took place during this cycle but it was so slow that it was caught and masked by the normal combustion initiated at the spark plug.

Cylinder pressure of cycle $\mathrm{n}^{\circ} 579$ clearly shows an occurrence of pre-ignition. Indeed, we can notice a light deviation at the time of the spark which is impossible unless the combustion began earlier. The associated processed image also shows a reaction zone which seems to be located in the background and once again on the exhaust side of the combustion chamber.

Cycles $\mathrm{n}^{\circ} 546$ and 285 reach roughly the same maximal cylinder pressure. However, we can notice that the pressure gradient is slightly higher for cycle $n^{\circ} 285$ which seems to be correlated with the stronger intensity on the associated raw image.

The final step of bulk auto-ignition is not visible on those four cycles because we made everything to avoid violent pre-ignitions with an early timing. However, some were inevitable and we managed to catch a few as we can see in Figure 9 where the combustion seems to concern a great part of the combustion chamber while the spark is just starting at that time.

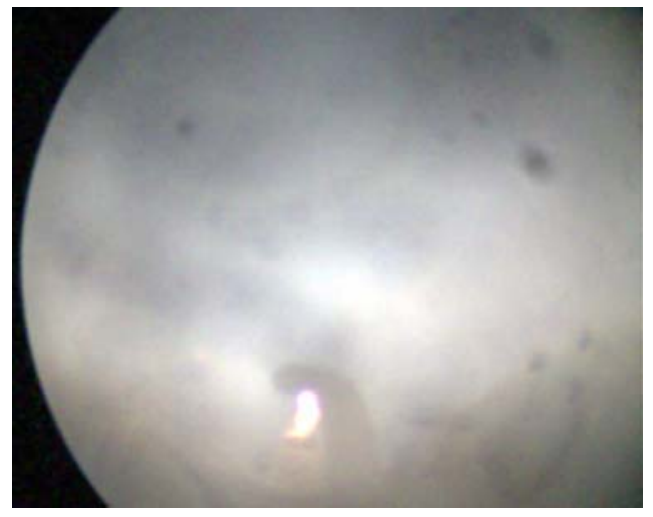

Figure 9 : Bulk auto-ignition at the same time as the spark (processed image)

Anyway, this final step is less interesting than the previous development of the combustion. Auto-ignition is mainly a result of the early timing of pre-ignition. The earlier the timing is, the more violent the final autoignition can be [2].

\section{STATISTICAL ASPECT}

\section{OBSERVATIONS}

Contrary to pre-ignition on hot surfaces, the pre-ignition that we observed is an unpredictable and sporadic phenomenon. On one hand, this kind of pre-ignition rarely appears and then only when the engine is run under heavy load but on the other hand a single occurrence can sometimes be really dangerous for the engine safety. An example is shown in Figure 10 with cycle-by-cycle maximal cylinder pressure values corresponding to the 300 first cycles of a whole recording of 1000 cycles. As we can see, the maximal cylinder pressure of the $38^{\text {th }}$ cycle nearly reached $20 \mathrm{MPa}$.

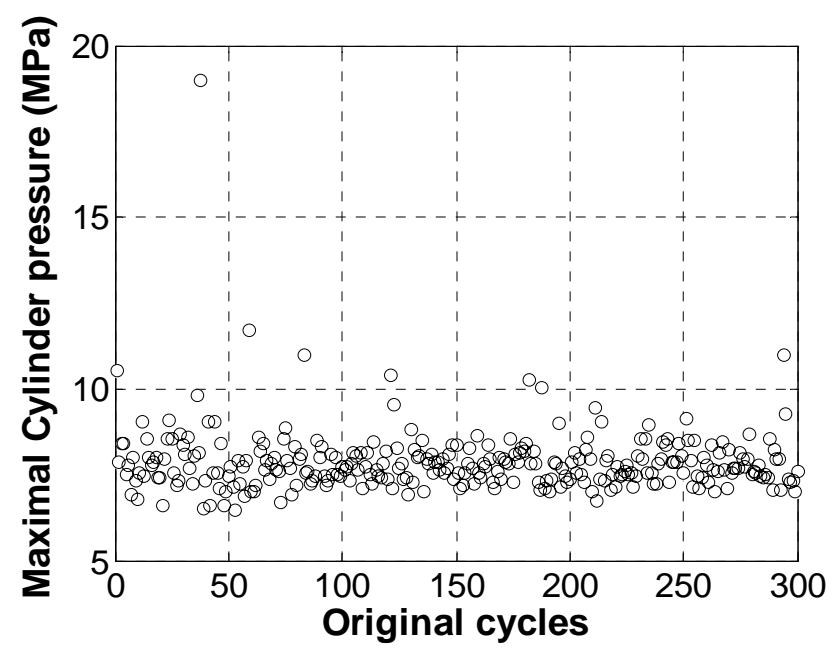

Figure 10 : Cycle-by-cycle maximal cylinder pressure (1000 rpm, IMEP $=2.5 \mathrm{MPa}$, DI mode, steady state warm operation)

Such an extreme maximal cylinder pressure could be disastrous for a normally designed gasoline engine. That is why we propose here to tackle statistically this problem to define new indexes quantifying the frequency and intensity of pre-ignition. That way, it would be possible to quantify the impacts of an engine settings or of an engine technical definition on its sensitivity to pre-ignition. The aim is to avoid extreme pre-ignitions like the violent one shown in Figure 10 by quantifying more precisely all the pre-ignitions occurrences whatever the engine load is.

However, the choice of the statistically observed value must be done carefully because it may hide physical effects. Cycle-by-cycle IMEP for example does not only depend on one parameter but on a combination of several parameters during the whole combustion process (in-cylinder charge motion, air-fuel ratio, heat transfers, ignition and injection characteristics, ... etc.). Thus, the characterization of an engine's sensitivity to pre-ignition through a statistical analysis of IMEP may hide some phenomena since a pre-ignition which would start only a few CAD before the spark could obviously look like a normal combustion and would not be necessarily detected through IMEP.

Therefore, the most logical and promising method would consist in supervising the first crank angle degrees of combustion, i.e. the ignition phase, through a statistical 
analysis of $10 \%$ Mass Fraction Burned [2], $5 \%$ MFB or even $1 \%$ MFB angles [8].

Once again, it must be kept in mind that the choice of the data sample affects the analysis. For example, the statistical analysis of the initiation phase (10\% MFB angle-SA) would mask the pre-ignitions' intensities while a direct statistical analysis of the $10 \%$ MFB angle would enable to keep the information of combustion timing within the cycle and then the pre-ignitions' intensities could also be analysed.

This kind of deductive reasoning could also be followed with other data than $10 \%$ MFB angle or IMEP. The maximal cylinder pressure analysis for instance could be more easily implemented and would be more suitable to characterize directly the intensity of pre-ignition and its effect on thermomechanical constraints which represent the crucial point for a highly loaded engine.

\section{DATA TREATMENT}

If we take a closer look at a bigger sample of cycles, we can notice that a whole range of pre-ignitions does exist (see Figure 11 which completes Figure 10 with the full recording of 1000 cycles). It is not a binary phenomenon with either a normal combustion, or a pre-ignition. Consequently, even if it is the easiest solution, it does not seem judicious to define a simple "on/off" criterion to decide if a given cycle corresponds to a normal or an abnormal combustion.

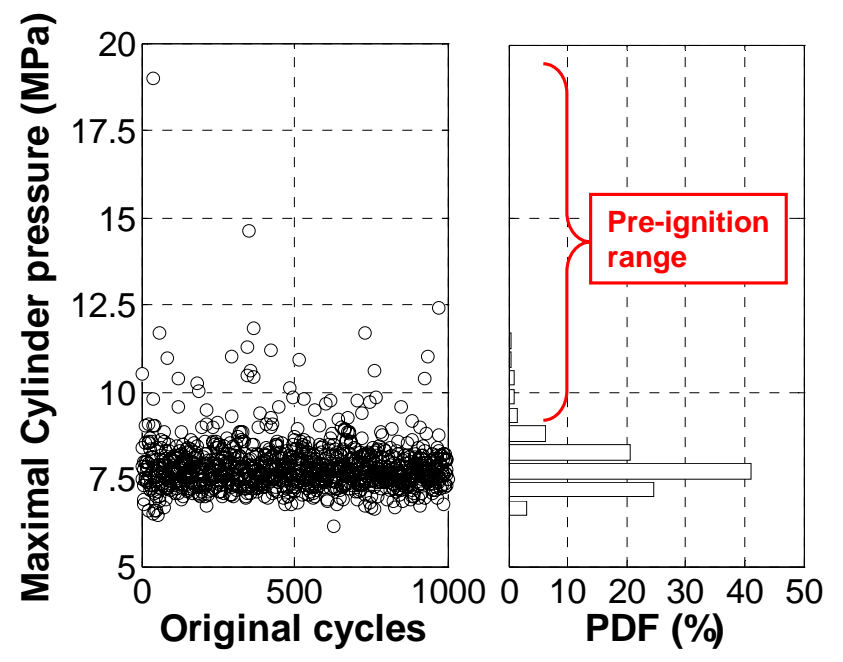

Figure 11 : Cycle-by-cycle maximal cylinder pressure corresponding to the full recording and associated probability density function $(1000 \mathrm{rpm}$, IMEP $=\mathbf{2 . 5}$ $\mathrm{MPa}, \mathrm{DI}$ mode, steady state warm operation)

A second way to qualify such a sample of cycles would consist in calculating values representative of the stochastic behaviour of the combustion. Mean and standard deviation are classically used to quantify the IMEP instability for example that is why we could first deduce that a basic criterion based upon them could help us to separate normal and abnormal combustions. The fact is those classical statistical indicators are very sensitive to outliers and can be quickly distorted when too many of those outliers occur.

For steady state operation, it means that a single occurrence of pre-ignition would be detected but the more pre-ignition there would be, the less efficient this basic criterion might be. For transient tests, the drifting characteristic of combustion would make this kind of criterion unsuitable even for successive normal combustions. It would be even worse if pre-ignitions occurred during this transient operation such as often happens. Classical statistical values would be frankly unusable because outliers would distort the drift.

\section{PRE-IGNITION DETECTION ROBUST STATISTICS}

Since classical statistical indicators turned out to be quite inefficient to accurately detect pre-ignition, a new methodology based upon robust statistics has been used. The main drawback of classical mean and standard deviation for example concern their great sensitivity to outliers. A few outliers in a given data sample are sufficient to significantly affect mean and standard deviation. This phenomenon is illustrated in Figure 12 with an artificial example consisting of 5 values. Four of them are between 20 and 22 and the fifth one is equal to 2. Regarding the global and mean tendency, one would intuitively say that the real mean of this dataset would be around 21. However, the last value strongly affects the mean and standard deviation calculations leading to a real calculated mean around 17 . The median which is the simplest and widest used example of robust indicators has also been reported in this figure and we can notice that this statistical indicator is not affected by the outlier (we refer to [19] for more details on robust statistics).

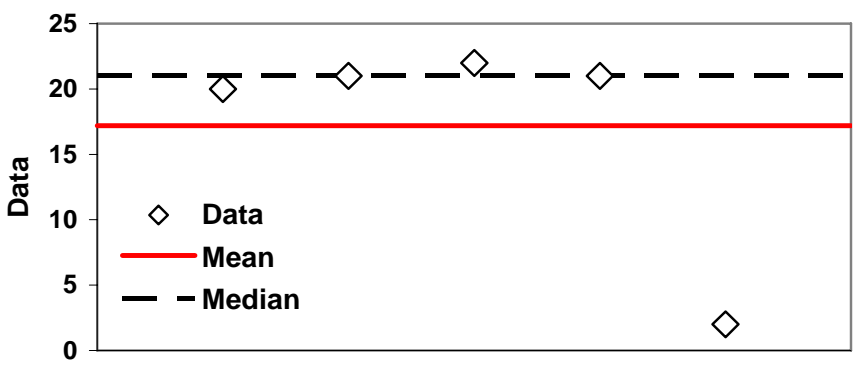

Figure 12 : Artificial example illustrating the impact of outliers on mean value

Engine designers frequently use stability criteria based upon classical statistics (combustion stability for example is commonly analysed with the coefficient of variation of IMEP). However, a lot of them often forget that a mean value is representative of a mean physical phenomenon only if each isolated sample is quite well represented by the mean. In our case, a pre-ignition occurrence is 
clearly brought to light by a reduced initiation phase or by an increased maximal cylinder pressure for instance. Therefore, robust indicators are needed to accurately set the limit between normal combustions and pre-ignitions. The precise determination of this limit is really important and allows a great efficiency in pre-ignition detection either during engine development on test bench or on board. Three examples are discussed here below to illustrate the efficiency of those robust indicators.

A first example for steady state operation is given in Figure 13. One thousand cycles were recorded at $1000 \mathrm{rpm}$ and an IMEP of $2.87 \mathrm{MPa}$ and the associated $10 \%$ MFB angles were calculated. Classical mean and standard deviations are shown in the top figure. Outliers occurrences result in a decreased mean and in an increased standard deviation while robust indicators shown in the bottom figure gives a much better characterisation of the main cloud of cycles corresponding to normal combustions (the duration of the initiation phase ranges between 10 and 13 CAD).
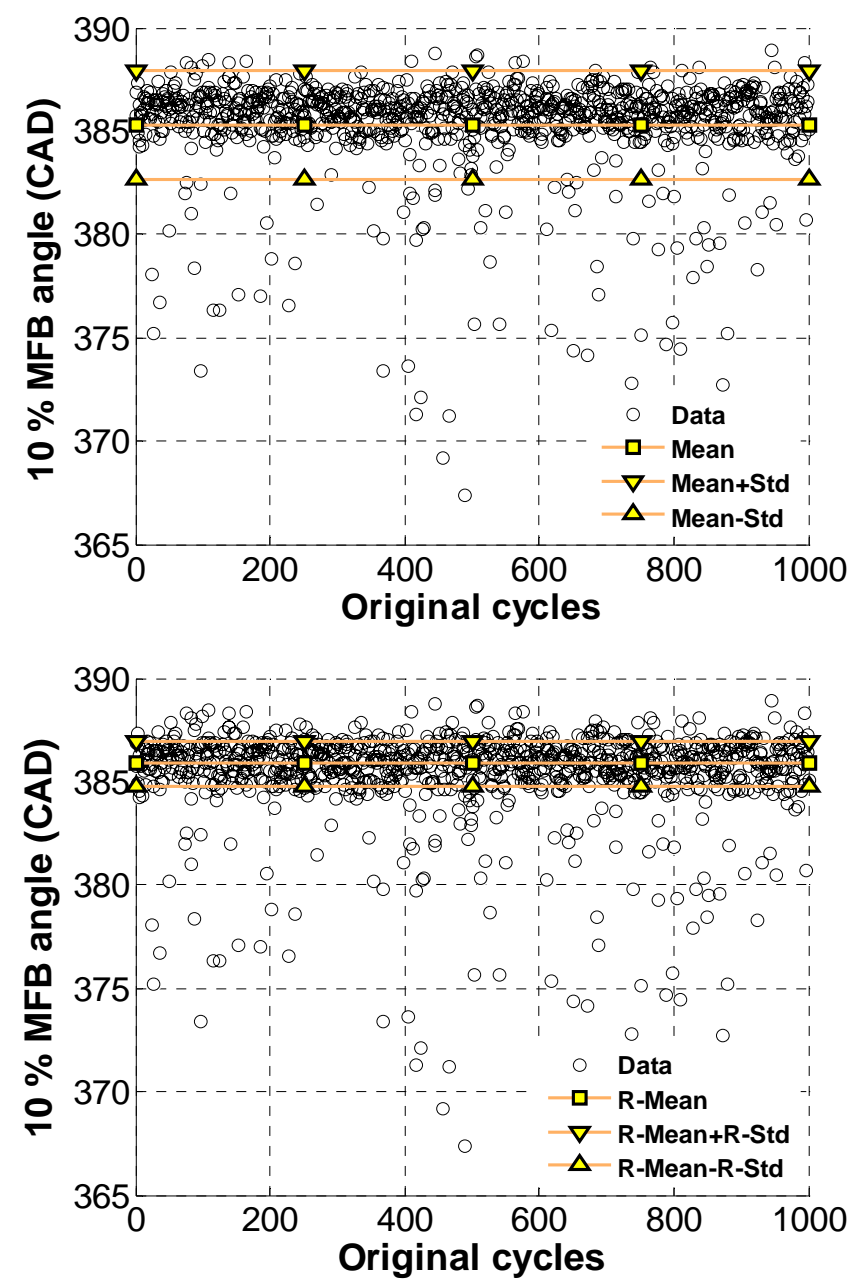

Figure 13 : Comparison of classical and robust statistical indicators $(1000 \mathrm{rpm}$, IMEP $=2.87 \mathrm{MPa}$, SA $=15$ CAD ATDC)

However, such a great quantity of data is not always available and this is why our new indicators were also used on the first twenty cycles of a recording. Thus, a reduced data sample and an on-line detection could be simulated. Our tests on this second example showed that our indicators were insensitive to outliers even in the case of a reduced sample (see Figure 14). This robustness is a great advantage to accurately detect preignitions cycle after cycle.
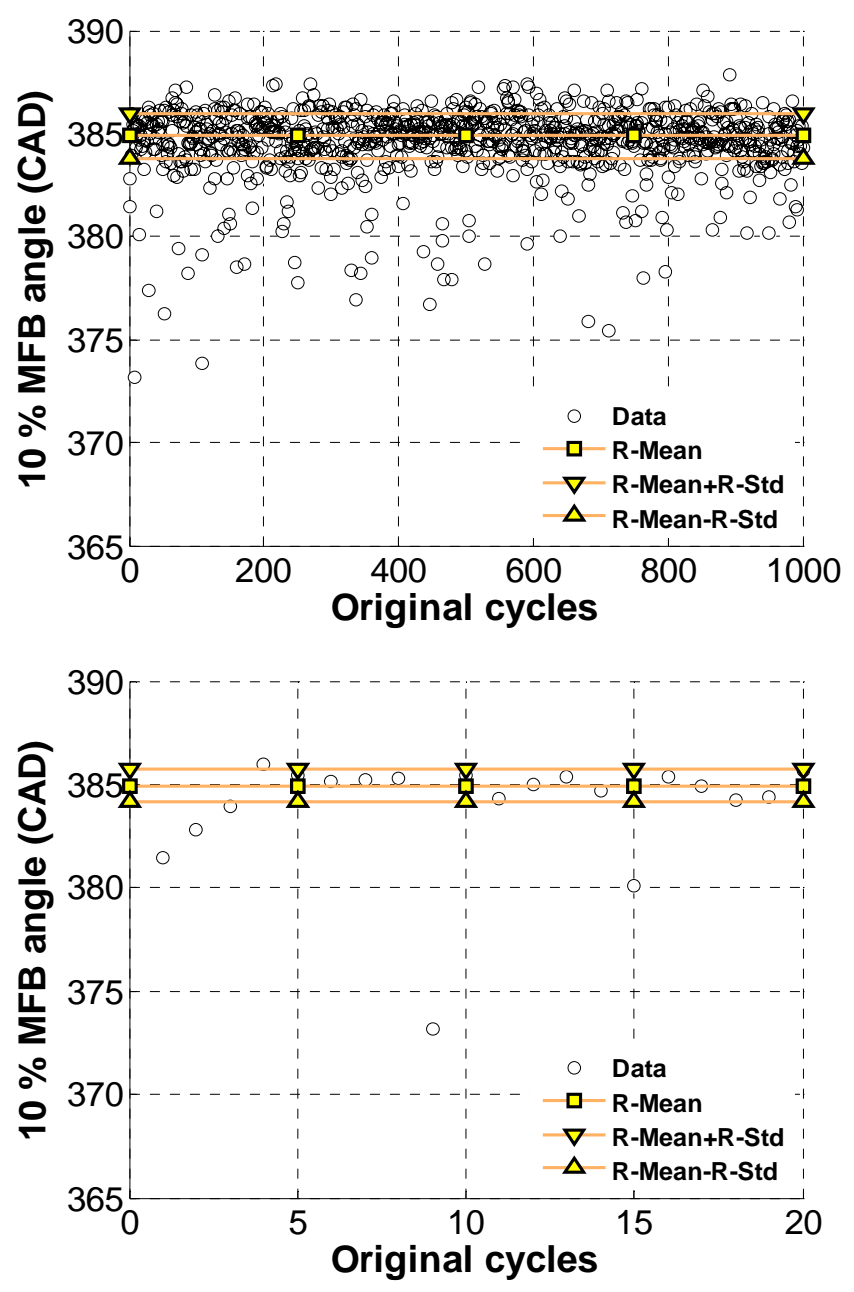

Figure 14 : Simulation of on-line detection based upon robust statistics $(1000 \mathrm{rpm}$, IMEP $=2.4 \mathrm{MPa}$, $S A=12$ CAD ATDC)

Data presented in Figure 14 were used for the third example. A quadratic cycle-by-cycle fluctuating drift was applied on those data to simulate a drift of ignition timing. This transformation is not meant to be representative of the real dynamic behaviour during a load transient. The first objective is to show that the robust statistical approach used here allows the following of the $10 \%$ MFB angle tendencies and the detection of pre-ignitions with an accuracy which is far better than with classical statistics (see Figure 15). 

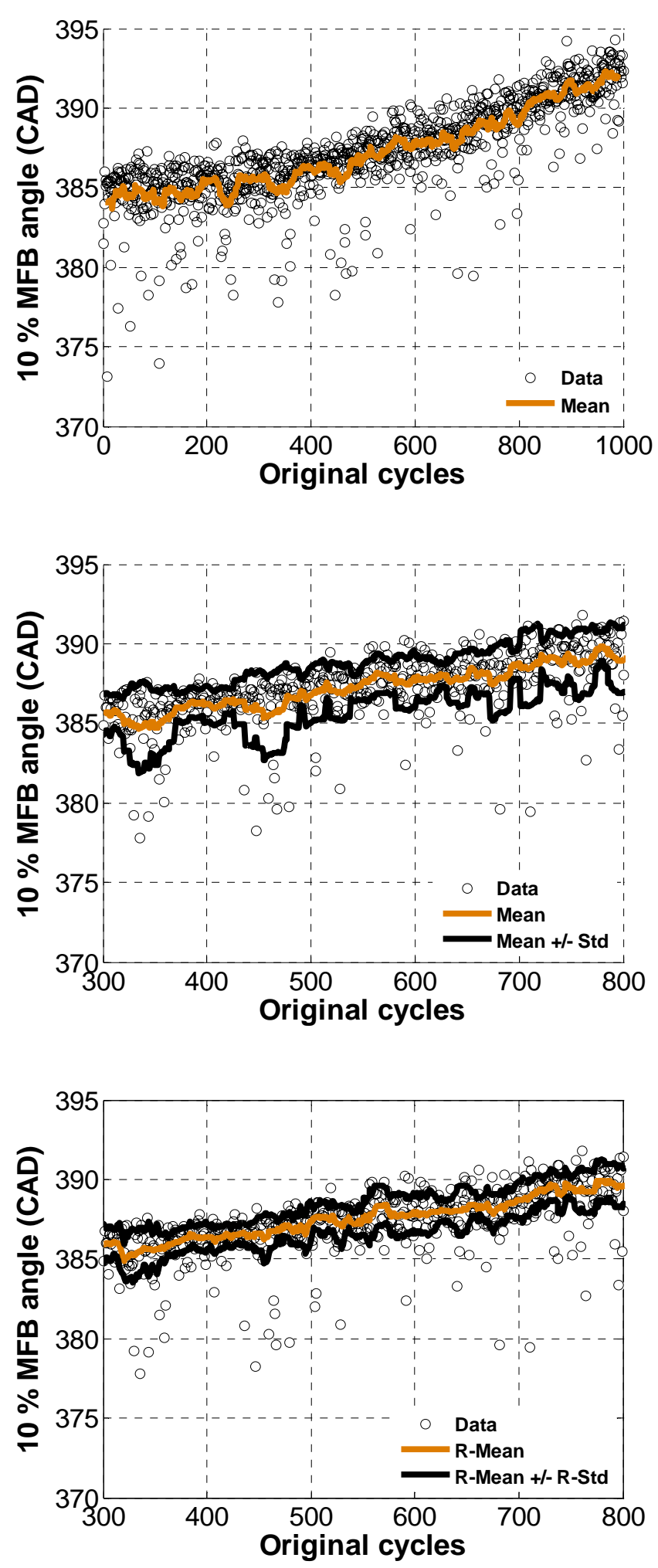

Figure 15 : Simulation of on-line detection based upon robust statistics during load transient $(1000 \mathrm{rpm}$, IMEP $=2.4 \mathrm{MPa}$, initial $\mathrm{SA}=12 \mathrm{CAD}$ ATDC)

From a global point of view, this kind of methodology could be easily widely applicable to control combustion stability whatever the combustion mode is (either for compression ignition or spark-ignition engines) and whatever the fuel is. It is quite a rare tool for engine designers but robust statistics proved that they could sometimes be really more adapted and efficient than classical ones.

\section{PRE-IGNITION CHARACTERIZATION MODELLING}

Independently of the detection aspect, a deeper analysis was performed through a statistical modelling of $10 \%$ MFB angle with the same two main long term objectives: the quantification of the occurrence frequency of preignitions during steady state operation and the detection of those abnormal combustions.

Dispersion associated with normal combustions (either for spark-ignition or compression ignition modes) are usually represented by a normal distribution. However, this simple well known symmetrical distribution is not always adapted. An example is given in Figure 16 with an experimental distribution of $10 \%$ MFB angles calculated in the case of a classical combustion mode. A normal distribution fitted on the experimental data is compared to an asymmetrical distribution to illustrate the lack of representativeness of the classical approach.

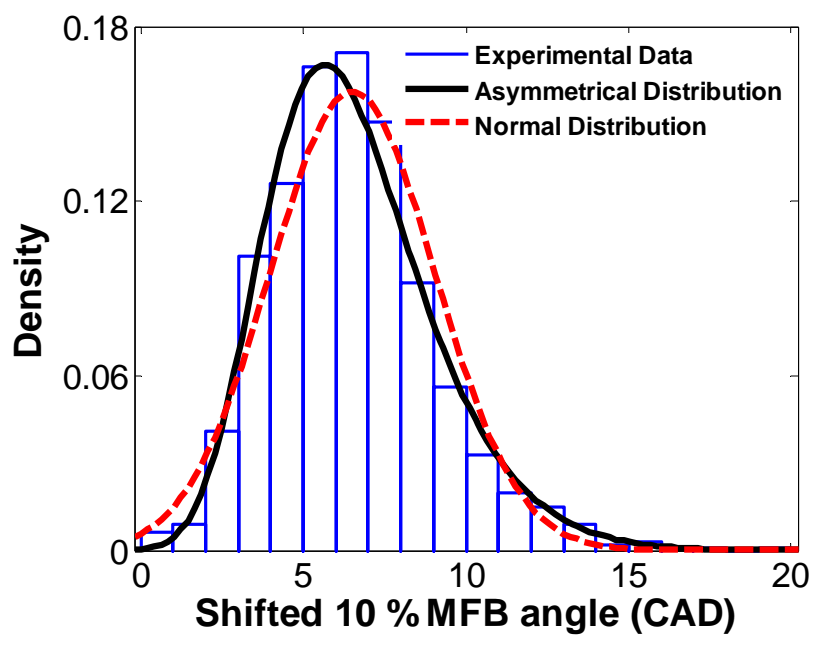

Figure 16 : Comparison of distribution fits obtained with a normal distribution and an asymmetrical one $(2000 \mathrm{rpm}$, IMEP $=0.5 \mathrm{MPa}$, steady state warm stoichiometric operation, minimum $10 \%$ MFB angle shifted to 0)

Pre-ignition occurrences modify the experimental distribution shape. As can be seen in Figure 17, $10 \%$ MFB angles associated with pre-ignitions make bigger the distribution tail on the low values side. On the contrary, the same approach on maximal cylinder pressure for instance would show that pre-ignitions make bigger the distribution tail on the high values side. 


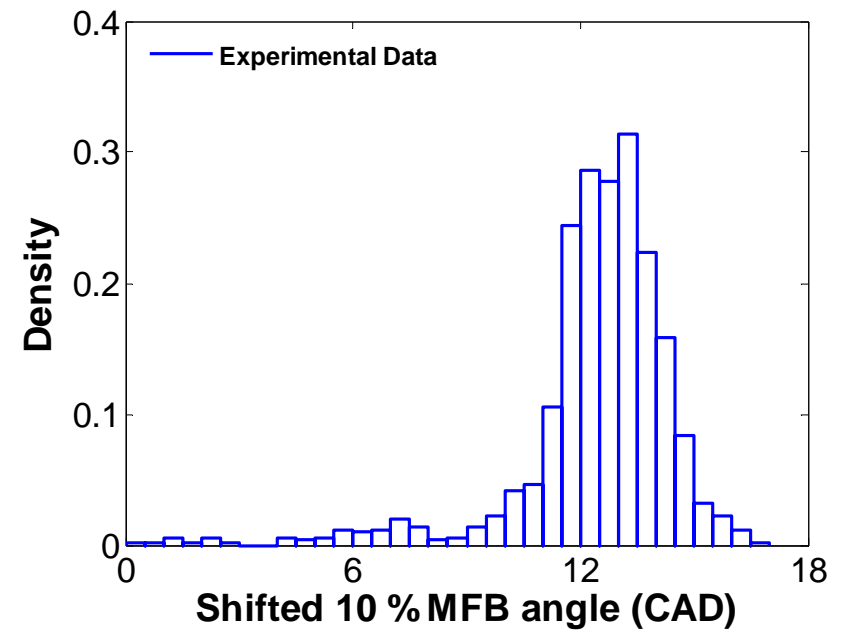

Figure 17 : Distribution of experimental data when pre-ignition occurs $(1000 \mathrm{rpm}$, IMEP $=1.75 \mathrm{MPa}$, steady state warm stoichiometric operation, minimum $10 \%$ MFB angle shifted to 0)

A normal distribution would never fit such data well and that is why we propose here a characterisation methodology leading to a reliable modelling of normal combustion and an accurate pre-ignition quantification. This deeper analysis can be used to compare sensitivities of different engines to pre-ignitions, but also to compare different operating points and compensate for the lack of efficiency of a simple couple of classical mean and standard deviation.

The data sample presented in Figure 17 for instance can not be directly modelled since a direct modelling would concern the whole sample with normal and abnormal combustions. Thus, it is first necessary to set aside abnormal combustions and not to use them for the distribution fitting. This sorting step which is the heart of our methodology was achieved through an iterative and automatic process allowing to find the optimal limit between normal and abnormal combustions. Once the limit defining abnormal combustions is optimally set, the sample corresponding to normal combustions can be fitted with a well chosen asymmetrical distribution (a non exhaustive list of distributions can be found in [19]).

This methodology was applied on the data presented in Figure 17 and the resulting modelling of normal combustions can be seen in Figure 18. The first sorting step of our methodology identified approximately 80 cycles with pre-ignitions. The modelling presented in Figure 18 therefore only concerns the 920 cycles left with a normal combustion.

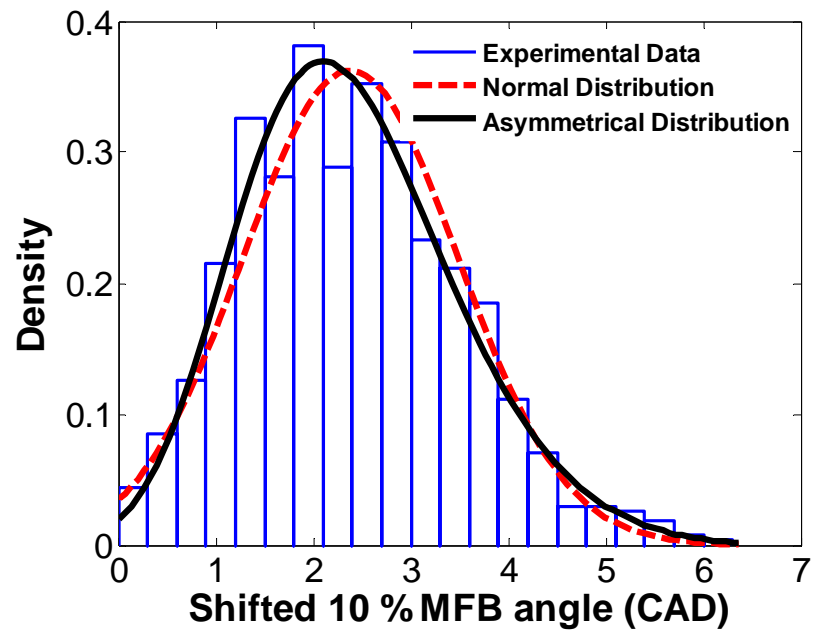

Figure 18 : Comparison of distribution fits of normal combustions with a normal and an asymmetrical distribution (1000 rpm, IMEP = $1.75 \mathrm{MPa}$, steady state warm stoichiometric operation, minimum $10 \%$ MFB angle shifted to 0 )

The occurrence frequency of pre-ignitions on the same operating point has also been evaluated with the first method based upon robust statistics (see previous section). The pre-ignition limit calculated with this first method and illustrated in Figure 19 perfectly determines normal and abnormal combustions. Both methods worked very well and resulted practically in the same pre-ignition frequency with $7.2 \%$ according to robust statistics and $8.0 \%$ according to modelling.

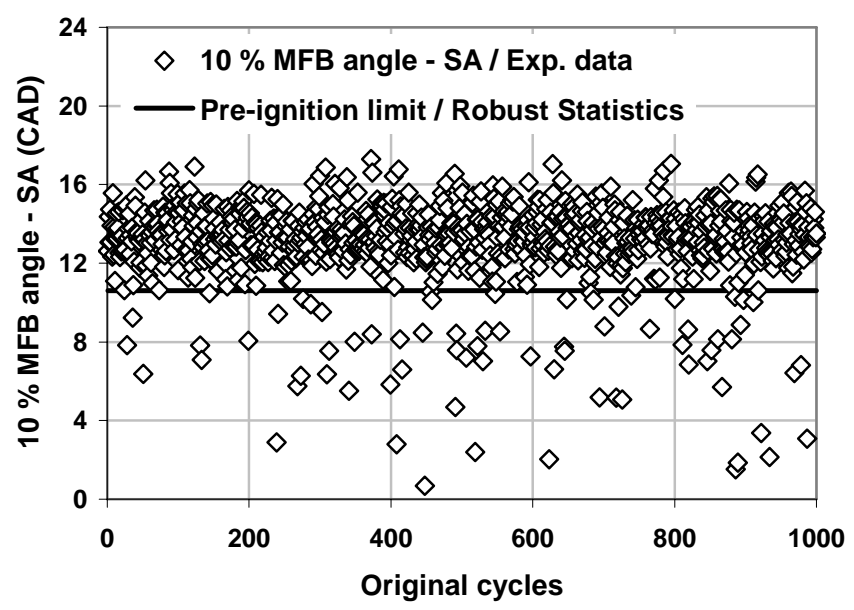

Figure 19 : Sorting of pre-ignitions based upon robust statistics $(1000 \mathrm{rpm}$, IMEP $=1.75 \mathrm{MPa}$, steady state warm stoichiometric operation, 72 pre-ignitions out of 1000 cycles) 
More generally, the skewness characteristic of experimental distributions concerning IMEP or $10 \%$ MFB angle for instance could be used more often to improve and to complete combustion analyses. This feature could be for example particularly well adapted to the control of stratified combustion stability but it could also be helpful for all the different combustion modes, whether assisted ignition modes or compression ignition modes.

\section{CONCLUSION}

Many hypotheses have been put forward to explain the violent form of pre-ignition found in new highly charged gasoline engines. The straightest way to discredit some of them is to directly visualise what is happening inside the combustion chamber. Results presented in this paper showed that it is possible to record and to analyse preignition development with simple and classical equipment. Further work is still needed to precisely identify the spatial pre-ignition origin and to analyse its repeatability through an advanced image processing.

Parametric studies have shown earlier that it was possible to slightly modify the intensity and the occurrence frequency of pre-ignition. The development of specific statistical tools allowed the quantification of those effects and the comparison of different engine configurations.

Classical statistics have shown their limitation to detect pre-ignition accurately. On the contrary, robust statistics turned out to be far more adapted and offer a reliable way to define normal and abnormal combustions. Satisfying results were obtained for off-line analyses of steady state and transient operations and also for simulated on-line analyses.

The modelling approach gives more details about the engine sensitivity to pre-ignition. Several statistical theoretical distributions can be used but the main point lies in sorting step requiring a well chosen criterion to optimise normal combustion modelling. The methodology proposed in this paper is quite well adapted for engine characterisation on test bench for instance but could also be adapted for on-board diagnosis.

A complete understanding of this pre-ignition phenomenon needs further analyses to develop a complete strategy from prevention to emergency actions through control.

\section{ACKNOWLEDGMENTS}

The authors would like to thank many colleagues at IFP for their precious assistance in this work, particularly L. De Francqueville, F. Vangraefschepe, T. Poulain, B. Thirouard and J.-P. Dumas.

\section{REFERENCES}

1. Heywood J. B., Internal Combustion Engine Fundamentals, McGraw-Hill, pp 450-490, 1988.

2. F. Vangraefschepe, J-M. Zaccardi, "Analysis of destructive abnormal combustions appearing at high load and low engine speed on high performance gasoline engine", The Spark Ignition Engine of the Future, SIA Congress, 2007.

3. M. Pirelli, F. Di Caprio, E. Torella, G. Mastrangelo, P. Pallotti, A. Marangoni, "Fun to Drive and Fuel Economy: the New 1,4 16v Turbo Gasoline Engine from FIAT Powertrain Technologies", SAE Paper 2007-24-0062, 2007.

4. Prochazka G., Hofmann P., "Autoignition on a highly supercharged gasoline engine and preventive measures". Internationales Wiener Motorensymposium. 2005

5. Bandel W., Fraidl G.K., Kapus P.E., Sikinger H., Cowland C.N., "The turbocharged GDI engine : boosted synergies for high fuel economy plus ultralow emission". SAE Paper 2006-01-1266, 2006.

6. Prochazka G., Hofmann P., Geringer B., Willand J., Jelitto C., "Comparison of the phenomena of autoignition in highly charged $\mathrm{SI}$ engines with external and internal mixture formation regarding influencing variables, mechanisms and preventive measures", SAE Paper 2006-05-0365, 2006.

7. Fraidl G. K., Kapus P., Philipp H., "Entwicklung robuster klopfsicherer Brennverfahren für hochaufgeladene Otto-Serienmotoren", Klopfregelung für Ottomotoren II - Trends für Serienentwickler, 2006.

8. P.-W. Manz, M. Daniel, K.-N. Jippa, J. Willand, "Preignition in highly-charged turbo-charged engines. Analysis procedure and results", 8th International Symposium on Combustion Diagnostics, BadenBaden, 2008.

9. A. Zahdeh, P. Rothenberger, J. Schäfer, "Diagnosing Engine Combustion Using High Speed Photography in Conjunction with CFD", 8th International Symposium on Combustion Diagnostics, BadenBaden, 2008.

10. K.-M. Han, W. Sauter, U. Spicher, "3D visualization of spark-ignition combustion : practical examples of flame propagation, abnormal combustion and controlled compression ignition", 8th International Symposium on Combustion Diagnostics, BadenBaden, 2008.

11. K.-M. Han, W. Sauter, U. Spicher, "ThreeDimensional Visualisation of Auto-Ignition Processes in Spark-Ignition Engines - Practical Examples of Abnormal Combustion and $\mathrm{HCCl}$ Auto-Ignition", The Seventh International Conference on Modeling and Diagnostics for Advanced Engine Systems, 2008.

12. P. Hofmann, M. Kieberger, B. Geringer, J. Willand, C. Jelitto, "Auslösemechanismen und Einflussfaktoren auf Vorentflammungsphänomene an hoch aufgeladenen Ottomotoren", 17. Aachener Kolloquium Fahrzeug- und Motorentechnik, 2008. 
13. V. Korte, H. Blaxill, G. Lumsden, D. Hancock, "Downsizing am Beispiel eines 1,2 । 3Zylindermotors", 17. Aachener Kolloquium Fahrzeugund Motorentechnik, 2008.

14. D. L. Donoho, "Denoising by soft thresholding", IEEE Transactions on Information Theory, pp. 933-936, 1993.

15. S. Mallat, "A wavelet tour of signal processing" Academic Press, 1998.

16. C. Chaux, L. Duval, J. Pesquet, "Image analysis using a dual-tree M-band wavelet transform", IEEE Transactions on Image Processing 15, no. 8, pp. 2397-2412, 2006.

17. C. Chaux, L. Duval, A. Benazza - Benyahia, J. Pesquet, "A nonlinear Stein based estimator for multichannel image denoising", IEEE Transactions on Signal Processing 56, no. 8, pp. 3855-3870, 2008.

18. P. J. Huber, "Robust Statistics", John Wiley and Sons, New-York, 1981.

19. Saporta G., "Probabilités, analyse des données et statistique", Technip, 2006.

\section{CONTACT}

Jean-Marc Zaccardi

IFP - Energy Applications Techniques Division

Engine System Analysis Department

j-marc.zaccardi@ifp.fr

Laurent Duval

IFP - Technology, Computer Science, and Applied

Mathematics Division

Control, Signal Processing, Real-Time Computing

Department

laurent.duval@ifp.fr

\section{DEFINITIONS, ACRONYMS, ABBREVIATIONS}

DI : Direct Injection

CAD : Crank Angle Degree

KL : Knock Limit

ATDC / BTDC : After / Before Top Dead Center

MFB : Mass Fraction Burned

ROHR : Rate Of Heat Release

SA : Spark Advance

IMEP : Indicated Mean Effective Pressure

CCD : Charge-Coupled Device 